\title{
Portella, intelectual do nosso tempo (e de outros tempos)
}

CARLOS GUILHERME MOTA

\author{
"Corre el tiempo, vuela y va \\ Ligero, y no volverá, \\ Yerraría el que pidiese, \\ O que el tiempo ya se fuese, \\ O viniese el tiempo ya." \\ D. Miguel de Cervantes
}

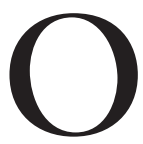

s 80 anos de Eduardo Portella e o cinquentenário da importante publicação que dirige, a Revista Tempo Brasileiro, obrigam a uma parada no tempo para apreciação de seu percurso intelectual, político e pessoal. Ensaísta e humanista, crítico da cultura e da vida contemporânea, observador empenhado da cena brasileira, sempre cultivou e mantém ao longo do percurso a visão cosmopolita inegociável no seu pensar o mundo de nossos dias. Um de nossos mais agudos intelectuais, dada sua reflexão interdisciplinar consistente e permanente.

"Não devemos ser movidos pelo rancor." Talvez seja esse um dos traços de Eduardo Portella que melhor o definem. A frase, dita logo após o atentado a bomba arremessada em 1968 nas instalações do Colégio do Brasil, por ele criado e dirigido, onde então se ministrava um curso sobre Herbert Marcuse, dá a medida do caráter do intelectual que não se dobrou à ditadura. Interrompida por curto período, a Tempo Brasileiro, sediada junto ao Colégio, logo retomaria sua rotina, sob a coordenação de seu irmão Franco Portella, responsável pela Casa Editorial Tempo Brasileiro, sediada no Rio de Janeiro, cuja revista completa 50 anos em 2012. "Fenômeno muito raro na América Latina a continuidade dessa revista", admirou-se o eminente historiador mexicano Leopoldo Zea.

Com efeito, ao longo de sua trajetória marcada por intensa produção, brilho e empenho, Portella não carrega nem coleciona rancores. Pois aprimorou a fórmula de Ortega y Gasset: "Sim, eu sou eu e minha circunstância; mas também procuro compreender as dos meus contemporâneos".

Embora inspirado em alguns pontos de sua caminhada pelo exemplo de Sartre (a quem trouxe pela primeira e única vez ao Brasil, tendo cultivado sua amizade durante anos), cedo iria descobrir que o inferno nem sempre são os 
outros, necessariamente... É em seu livro Literatura e realidade nacional, de 1963, que se encontra mais nítida a inspiração sartriana na procura e definição do sujeito histórico, do outro, do engajamento. Procura incessante que o levaria, passada a ebulição existencialista, a procurar novas interlocuções e aprofundá-las interdisciplinarmente no decorrer de sua caminhada intelectual e política.

Como veremos, na virada dos anos 1950, Portella passaria a se alinhar progressivamente nos campos da esquerda, de modo crítico e independente. ${ }^{2}$ Mantendo distanciamento em face dos dogmatismos e do que denominou "política de uma nota só", foi no pensamento de Albert Camus (1913-1960) que na maturidade colheu a melhor referência. Indagado se era de esquerda, Camus respondeu: "Sim, apesar de mim e apesar dela". ${ }^{3}$

Como se pode acompanhar nas páginas da revista que dirige há 50 anos, seu diretor e animador Portella tornou-se destacado personagem de nossos tempos plurais, que por vezes caminha na contramão das trilhas da cultura contemporânea. O que apresentaremos em seguida é, menos que um desenho, um debuxo de uma personalidade cuja vida se desenrola na intersecção de muitos planos, em escalas variadas.

Como neste rude exercício da difícil arte da simplificação descrevê-lo torna-se quase impossível, ressaltaremos apenas alguns traços de sua existência em (apenas) três ou quatro dimensões, que aliás se misturam. A humana, ou seja, seu perfil/trajetória enquanto pessoa; a dimensão enquanto homem de Letras, sobretudo seu lugar como crítico da cultura; a dimensão do político educacional e cultural; e, enquanto ator sempre presente em tantos tópicos da cena contemporânea, a dimensão do teórico da referida interdisciplinaridade consistente, militante da crítica e questionador de teorias do conhecimento.

$\mathrm{Na}$ entrada do terceiro milênio, após longa série de embates com os poderes políticos e culturais, tanto no Brasil como no exterior, o intelectual permanece ativo e como sempre inquieto, porém mais sereno. Portella é intelectual no sentido pleno da palavra que, por meio de civilizadora postura docente, mescla sabedoria com espantosa capacidade de atualização e socialização de seus conhecimentos. Docência viva, contínua, por vezes desafiadora, que envolve todos aqueles que gozam do privilégio de com ele conviver, e com sua persona. De aprender com seu ativismo crítico, frequentemente anticonvencional porque banhado em inegociável sense of humor, moeda rara nos meios intelectuais de hoje.

A pessoa de Eduardo Portella faz-me lembrar o que de Borges disse o crítico Antonio Muñoz Molina em 2007, com meio sorriso na face: "Não sem malevolência, V. S. Nipaul escreveu que, em seus últimos anos Borges, de tanto ser entrevistado, havia acabado por converter-se em sua própria entrevista".

De fato, Borges, o notável escritor argentino "se convertera em personagem público também chamado Borges" "... Percepção semelhante à de Molina 
em sua juventude, ao comentar respeitoso encontro seu com o poeta espanhol Rafael Alberti em Granada no começo dos anos 1980, quando "era jovem e propenso à reverência": custara a perceber que "aquele homem estava disfarçado de algo, estava interpretando um papel, da mesma forma que Borges resignou-se na maturidade 'a hacer de Borges'".

A diferença é que, ao contrário de Borges, Alberti mostrava-se muito fatigado, gasto, diferentemente de Portella, sempre vivaz e produtivo. Assim, não vale o escrito, pois nada disso serve para definir a persona de Eduardo Portella, intelectual público ativo, avesso à reverência, à "canonização"...

\section{O perfil e a persona}

"Não sou tema de mim mesmo."

Eduardo Portella, na Câmara dos Deputados em Brasília, $1979^{6}$

Uma biografia intelectual aproximadamente correta de Eduardo Portella só poderia ser escrita se consideradas as várias dimensões e os valores geracionais que atravessam e compõem sua personalidade, valores por ele hauridos e quase sempre reformulados que se misturam em sua vida e em sua mente inquieta. Pois, além de estimulante, não é fácil acompanhá-lo ao longo desses 80 anos em todos os movimentos, atuações e produções nos diferentes níveis de realidade e contextos histórico-culturais pelos quais transitou - e nos quais continua a atuar, enraizado no Brasil -, nem nas disciplinas do conhecimento que cultiva, ou na intensidade das discussões com seus contemporâneos. ${ }^{7}$ Tudo provocando o turbilhão criativo permanente que o envolve e alimenta, e aos seus interlocutores, amigos e também uns raríssimos e datados desafetos. Ao longo do tempo de sua vida, cultiva metódica e rigorosa disciplina intelectual, e abre janelas para respiração de ares renovados, essenciais para sua/nossa atuação crítica no abafado sistema ideológico-cultural da chamada cultura brasileira.

$\mathrm{Na}$ maturidade, mantém o modo bem-humorado do jovem precoce dos verdes anos de formação na Bahia, no Recife, depois Paris, Roma e, mais demoradamente, em Madri. Até assentar-se por fim no Rio de Janeiro.

Com o correr do tempo, Portella abriu-se para o mundo, galgando postos de real importância nas galáxias da cultura internacional. Irreverente quando necessário, sabe apreciar e cultivar figuras e valores em que reconhece qualidade, desde que escrutinados em sua oficina crítica, no seu scriptorium. Discreto, não considera completa sua formação até hoje.

Seu nome já despontara nos albores dos anos 1950, mas só se afirmou, como referência no cenário literário-cultural brasileiro, depois de passados alguns anos da consolidação do grupo-geração renovador de Celso Furtado, Florestan Fernandes, Paulo Freire, Milton Santos, Antonio Candido, Darcy Ribeiro, entre tantos. Ou seja, na virada dos anos 1950 para os 1960. 
Com efeito, Dimensões I (de 1958), Dimensões II (de 1959, então com o subtítulo O livro e a perspectiva), e Dimensões III (de 1965, que saiu com subtítulo Cultura brasileira em curso) tiveram impacto e ganharam prêmios. Direta ou indiretamente, tais escritos, e mais os livros África: colonos e cúmplices (1961), Politica externa e povo livre (1963) e Literatura e realidade nacional (1963) se voltavam para a temática da identidade nacional (o "projeto nacional"), todos perguntando qual a natureza desta sociedade, como modernizá-la e tirá-la do atraso.

No compasso daquele tempo, indagava ele como podiam persistir no país tantas resistências à mudança, como demolir o Brasil "arcaico" e quais os caminhos para a atualização de nossas instituições. Como requalificar cientistas e a universidade para responder a tantos desafios? Qual o papel dos intelectuais em países do Terceiro Mundo, e assim por diante. Também no Instituto Superior de Estudos Brasileiros (Iseb), no Rio de Janeiro, indagações e estudos dirigiam-se mais diretamente no sentido da busca de uma filosofia brasileira (ou seja, "adequada à realidade brasileira"), com Álvaro Vieira Pinto, dos fundamentos da formação cultural brasileira, com Roland Corbisier, das instituições políticas brasileiras, com Hélio Jaguaribe, de uma história "brasileira" do Brasil, com Nelson Werneck Sodré.

Naquele processo de aceleração histórica e revisionismo nos diagnósticos sobre os rumos do país, logo surgiria um conjunto de análises em que se procurava compreender a formação do Brasil, com as obras marcantes de Celso Furtado, Raymundo Faoro, Antonio Candido, Florestan Fernandes, Manuel Correia de Andrade, Wanderley Guilherme, entre outros. Na literatura com Guimarães Rosa, como na educação em que se disseminavam as técnicas de alfabetização de Paulo Freire, um outro Brasil despontava, e assim em todos os campos. Ensaios e diagnósticos críticos como os de Caio Prado Júnior e Furtado versavam sobre a "pré-Revolução Brasileira" ou sobre os limites da revolução, que aliás não ocorreu... De todo modo, pensava-se intensa e criticamente o Brasil.

Naquele começo dos anos 1960, o momento era de reflexão, de redescobrimento do Brasil em perspectiva histórica e de pesquisas inovadoras sobre o país. No mesmo contexto, e desde os anos 1950, a Escola Superior de Guerra também vinha, silenciosamente, fermentando suas teorias sobre os "destinos da Nação", com o coronel Golbery do Couto e Silva à frente. Curioso é que em suas bibliografias constavam alguns textos de Hannah Arendt e o clássico de David Riesman, A multidão solitária. Intelectuais como José Honório Rodrigues, autor do contundente Conciliação e reforma, chegaram a ser convidados a palestrar na ESG, da qual depois se afastaram, como menciona em seu livro Aspirações nacionais: um desafio histórico-politico.

Enfim, todos procuravam a nova identidade nacional, mas encontraram um subdesenvolvimento generalizado, da educação à economia, bem como o "peso da herança colonial", expressão corrente em inúmeros textos e debates 
da época. O país corria risco com o "vazio mental" temido por Karl Mannheim, muito lido então pela intelligentsia do país. O déficit educacional era tremendo, o que tornava o país frágil no concerto internacional, a despeito dos discursos e projetos salvacionistas. "Atenção", alertava o educador Anísio Teixeira envolvido no reformismo daquela quadra histórica, pois "o Brasil é o país da miséria farta", acomodado...

Observada no arco do tempo, a mudança profunda no plano intelectual foi o aprofundamento da perspectiva histórica: da antiga questão proposta por Mário de Andrade e Cruz Costa nos anos 1940 ("quem somos nós?") passou-se a indagar, mais concretamente virada da década de 1950, "que somos nós?", com Celso Furtado e outros estudiosos à frente. A indagar e agir.

Foram incontáveis os impasses econômico-sociais, institucionais e ideológicos surgidos nas lutas pelas reformas, no campo como nas cidades, que nos libertassem das amarras de nosso passado estamental-escravista ainda presentes no universo político-cultural marcado pelo mores coronelista, agudizados com os desdobramentos do populismo e do clientelismo urbanos. Enfim, descobriam-se os limites históricos que bloqueavam o esperado "take-off" capitalista (noção veiculada por W. W. Rostow), como também a sonhada Revolução... Aberto por embates e novas formulações para um projeto nacional, o caminho trilhado pelos intelectuais foi curto, grosso modo de 1955 a 1965, ou mais concretamente, na virada de década, quando se desencontraram no país valores e tempos históricos muito distintos, logo conflitantes: a moderna Brasília e o desenvolvimentismo industrial tendo como contraponto as Ligas Camponesas e a violência das rústicas e brutais elites agrárias...

Naqueles anos, impunha-se o combate ao latifúndio, denunciado nos estudos de Manuel Correia de Andrade, Caio Prado Júnior e Heitor Ferreira Lima, e também ao coronelismo analisado por Vítor Nunes Leal, Marcos Vinicios Vilaça e Roberto Cavalcanti de Albuquerque, e também ao patrimonialismo, revisto em perspectiva histórica por Raymundo Faoro. O combate ao atraso na educação com as ideias de Anísio Teixeira e Darcy, e ao analfabetismo com o método recém-testado de Paulo Freire, beneficiava-se com os avanços dos estudos de campo da sociologia, da antropologia, da história, da pedagogia, da geografia, da literatura. Descortinavam-se novos horizontes, assistia-se a um novo redescobrimento do Brasil, aprofundando o que ocorrera na década de 1930. As teorias então formuladas para a superação do subdesenvolvimento e as ações reformistas revelavam-se extremamente importantes, originais, tecnicamente bem elaboradas e algumas delas até bem aplicadas, como no Rio Grande do Norte ou na Sudene.

O Brasil alinhava-se com os movimentos terceiro-mundistas, despontando como possível liderança mundial. Movimentos sociais no campo, nas cidades, a fermentação na universidade, nos sindicatos, na diplomacia, na presidência da República e até em alguns segmentos das Forças Armadas permitiam imaginar 
estarmos vivendo a "Pré-Revolução Brasileira”. Mais à esquerda, agrupamentos político-ideológicos imaginavam estar o país no caminho de uma revolução socialista. O que, entretanto, ocorreu foi a descoberta da complexidade insuspeitada do capitalismo dependente, pouco antes do golpe civil-militar de 1964, que desembocaria no capitalismo selvagem do "milagre econômico", com fechamento do regime e abolição das liberdades civis, após o golpe dentro do golpe em 1968.

Foi naquele contexto de fermentação de projetos, utopias e impasses que a biografia de Eduardo Portella se enriqueceu, ganhando densidade. Embora vivesse em universo mais voltado pela literatura, abriria asas para voos mais altos no final dos anos 1950. Da experiência como assistente do Gabinete Civil no governo de Juscelino, posto assumido em 1956 com apenas 24 anos, até o governo Jânio Quadros, quando articulou projeto de aproximação com a África, por meio do Instituto Brasileiro de Estudos Afro-Asiáticos, o jovem Portella se politizou, e aprendeu. Aos 28 anos e alguma experiência, assumiu a chefia de gabinete da Secretaria de Educação e Cultura do antigo Estado da Guanabara, onde testou ideias e aplicou projetos de educação e cultura, e formulou "conceitos que mais tarde aplicaria no Ministério de Educação e Cultura e Esportes quando esteve ministro, em 1979-80". ${ }^{8}$

Recorde-se que, na América Latina, durante a breve presidência de Jânio Quadros, assistiu-se a uma vaga político-ideológica terceiro-mundista contra a maré imperialista montante, que até levaria o controvertido mandatário a reunião em Havana, foco central da Revolução, acompanhado do então chanceler Afonso Arinos. Naquele contexto e clima, o fato positivo é que foram criados Centros de Estudos Afro-Asiáticos no Rio, do qual foi presidente o jovem Portella, e também em Salvador, nos quais se cultivavam o ensino do iorubá, aulas de história da África de arte africana e outros estudos. Novos ventos, a universidade brasileira - até mesmo na Universidade de São Paulo, pouco aberta às aspirações terceiro-mundistas - começava a se abrir para a cultura africana, recebendo alunos das ex-colônias francesas, portuguesas e de outras regiões.

Naquele clima, José Honório Rodrigues, interlocutor de Portella, que lecionava nos cursos do Itamaraty, migrou de suas pesquisas em história do Brasil colônia para escrever Brasil e África: um outro borizonte, publicado em 1961, título aliás sugerido por Guimarães Rosa. Portella também escreveria o citado livro África: colonos e cúmplices, todos proibidos pelo governo de Salazar. ${ }^{10} \mathrm{~A}$ mãe-África, ligada às "nossas raízes", parecia então mais próxima de nós do que hoje... A diplomacia também despertava para o que se denominou Política Externa Independente, formando mentes como as de Ítalo Zappa e de jovens como Alberto da Costa e Silva, hoje o historiador brasileiro de maior renome mundial voltado para o continente africano. Todos interlocutores ou amigos de Portella.

Mais tarde, Josué Montello fez notar que 
o renome de escritor - de grande escritor, militando no ensaio e na crítica literária - é contemporâneo de Brasília. A maturidade do ensaísta e crítico tem assim concordância com a maturidade da nova capital, que se realizou e completou, ainda sob os olhos de seu fundador, o Presidente Kubitschek, de quem Portella foi colaborador destacado. ${ }^{11}$

De fato, com apenas 23 anos, Portella atuou ao lado de Francisco de Assis Barbosa e outros, como assistente do Gabinete Civil da Presidência da República, posição que lhe propiciaria convivência, ao longo da vida, com personagens do mais alto nível cultural e político como Furtado, Darcy, Anísio, Hermes Lima, San Tiago Dantas, e também com “escolados” políticos mineiros que cercavam Juscelino, como Tancredo Neves e José Maria Alckmin. A partir do principal centro do poder da República, adquiriu uma visão mais ampla daquilo que se denominava "Questão Nacional", sempre tratada nos debates em diversos fóruns do país em que se discutiam as reformas, o desenvolvimento, a crítica às teorias dualistas sobre o desenvolvimento e os caminhos para a superação de nosso atraso.

\section{Portella, homem de esquerda}

“...mis muros de fuego son”.

Provérbio mudéjar

A biografia intelectual de Eduardo Portella já foi competentemente traçada por vários autores, amigos, críticos. Mas talvez valha aqui realçar seu perfil de homem liberal e de esquerda, que é. Qual esquerda, porém?

Cosmopolita como poucos intelectuais progressistas de fato o são, abriu-se ele para o mundo, paradoxalmente, na Espanha franquista. Antenou-se nas ideias e pessoas de Ortega y Gasset, Bousoño, Zubiri e outros. De Ortega, marcou-o a Historia como sistema, de 1941, tanto em inspirações para abertura de novos temas (sempre perspectivados historicamente) como no plano estilístico. Ou seja, em seu modo de pensar e escrever. Inspirou-se também em ações do tipo "Archivo de la palabra", em que Ortega gravou discos com seus textos filosóficos em 1932, com formulações polêmicas do tipo "No hay propiamente 'historia de las ideas", ou ainda "La historia que 'termina' y no acaba”... Enfim, como não enxergar em posturas e textos de Portella, passados tantos anos, o peso de frases do tipo "El hombre no tiene naturaleza, sino que tiene historia", ou ainda "El hombre no es, sino que va siendo esto o lo otro"? Como Ortega, Portella transformou-se filosoficamente em "peregrino do ser". Mas também entusiasmaram-lhe interpretações mais avançadas, internacionalistas e revolucionárias que animavam as vanguardas culturais, políticas e ideológicas dos anos 1950, quando ainda permaneciam vivos na memória coletiva os recentes embates e tragédias da Guerra Civil de 1936 e os desdobramentos da Segunda Guerra Mundial. ${ }^{12}$

Já se distanciando da adolescência, com ecos e heranças dessas guerras em sua mente, Eduardo descobre nos anos 1950 o Humanismo liberal. E, passados 
poucos anos, o terceiro-mundismo e a descolonização das regiões de passado colonial, que mudariam sua escala intelectual ao dialetizar o mundo em processo de cisão: de um lado, o crescente American way of life penetrando no universo brasileiro e latino-americano, ou seja, o imperialismo norte-americano, em contraposição ao bloco da ex-Cortina de Ferro, do chamado "Socialismo real" sob as ordens de Stalin, o ambíguo herói da guerra, desmascarado só em 1956. Tempos de revisão provocada pelos movimentos mundiais de independência das colônias, que descortinavam outros horizontes para as mentes antenadas como a de Portella, Darcy, Furtado, Inácio Rangel, Milton Santos e centenas de outros intelectuais de variados ofícios.

Portella tornara-se um Inteirista, na conceituação de Miguel de Unamuno, ou seja, já não distinguia a política da cultura, a liberdade de pensamento da liberdade política, a literatura da História. Pois, a despeito das atribulações políticas que marcariam seu caminho, sempre optava por manter, com registro crítico apurado, diálogo democrático e aberto com os grupos políticos progressistas e intelectuais da hora, como Jorge Amado, Sartre, Darcy, bem como com as lideranças da África de língua portuguesa e de outros países africanos, latino-americanos e, um pouco menos, asiáticos. Desse modo atuou quando assumiu postos no governo $\mathrm{JK}$, depois como professor universitário, mais tarde como ministro de Educação e Cultura, depois na direção da Unesco e na presidência da Fundação Biblioteca Nacional.

Inspirado pela experiência do Colégio de México (e tendo conhecido de dentro o Collège de France), criou o Colégio do Brasil, no Rio de Janeiro, em que atuou intensamente com seu irmão Franco Portella, editando uma das principais e mais duradouras publicações no campo da cultura, a Revista Tempo Brasileiro, e livros. Reuniu no Colégio e na revista intelectuais de diversos quadrantes, na busca das especificidades dos problemas nacionais, em suas variadas dimensões, sempre examinados "a quente" pelo ângulo da análise interdisciplinar.

Sua atuação como ministro da Educação, Cultura e Desportos no governo Figueiredo, no final da ditadura civil-militar de 1964, foi arriscada em todos os sentidos, inclusive pessoal. Uma oportunidade ímpar para atuar no processo de abertura do governo civil-militar, que tentou aproveitar. Porém, como seus pares mais à esquerda acolheriam sua presença num governo militar? Ademais, viu-se obrigado a mudar do Rio para um hotel em Brasília, com sua mulher Célia, participante sempre atenta e suave em suas lides, e a filha Mariana, ainda bebê (hoje doutora em Economia, Comunicação e Cultura).

Um ministro nada convencional, à la Trudeau, o primeiro-ministro canadense modernizador, Portella levou ares renovados para a capital da República naqueles anos cinzentos. Mas por pouco tempo, logo se veria, pois um general "linha-dura", Medeiros, e um outro Portela, o general Jaime Portela, eram avessos à abertura do regime. Até porque, o Portela general, além de ter sido 
um dos militares que tentaram impedir a posse de Juscelino em 1956, fora um dos articuladores do AI-5; e, depois, secretário geral do Conselho de Segurança Nacional na ditadura e presidente do IPM sobre o Partido Comunista Brasileiro. General da linha-dura que um terceiro Portella, o habilidoso e liberal Petrônio Portella, ministro da Justiça da abertura política, não conseguiu amaciar... O professor Portella teve que deixar o governo e aplicar suas ideias em outras frentes.

Inconscientemente ou não, o ainda jovem Portella construíra passo a passo uma persona que, a partir de certo ponto, como que adquiriu vida própria, passando a animar e dominar toda a existência de professor, desde cedo defensor e aplicador da Pedagogia da Qualidade, logo escritor conhecido, depois político controvertido, administrador cultural internacional e nacional brilhante, além de reconhecido crítico da cultura. Seu principal traço, sua atividade central: acompanhar crítica e dinamicamente o curso do tempo, a respiração das produções culturais, sobretudo literárias. Dialeticamente. ${ }^{13}$

Portella sabe-se beneficiado pela circunstância de ter encontrado em sua vida professoral algumas de suas fortes influências intelectuais, como ele próprio apontou em 2002, na alocução final quando das homenagens por seus 70 anos, ao receber o título de Professor Emérito da Universidade Federal do Rio de Janeiro, da qual participaram vários acadêmicos. E se situou:

Descendo de uma linhagem pouco comum: Alceu Amoroso Lima, Sousa da Silveira, Manuel Bandeira, Jorge de Lima, Ernesto Faria, Serafim Silva Neto, Celso Cunha, José Carlos Lisboa, Afrânio Coutinho, Thiers Martins Moreira, Roberto Alvim Correa, Augusto Meyer, Mário Camarinha da Silva e tantas figuras exemplares, todas elas inesquecíveis professores de minha Faculdade. ${ }^{14}$

Naquela oportunidade, voltou a bater nas teclas da Pedagogia da Qualidade e da interdisciplinaridade. Captou ele as lições de Anísio Teixeira: revalorização do professor, eis para ele a chave do problema, no reconhecimento daquele "que professa, conduz, leva adiante, ensinamentos a cada instante desestabilizados. Ver, rever constituem tarefas desse profissional mais ou menos desempregado" (p.4). Outro ponto de ataque é "a defesa da interdisciplinaridade, contra a lassidão da pesquisa monodisciplinar, amparada por agências oficiais de financiamento, que bloqueou ou perturbou fecundos movimentos da vontade de pensar".

Dentre os citados intelectuais-professores, Portella destaca Afrânio Coutinho, por ter implantado os primeiros programas sistemáticos de pós-graduação em Letras. No início dos anos 1970, Afrânio, então diretor da Faculdade, confiou a coordenação geral dos cursos a Portella que, na apresentação do programa, definiu a graduação como "o lugar do saber sabido e a pós-graduação o lugar do saber por saber" (p.5). No seu agradecimento, também destacou a pessoa do brilhante e saudoso Celso Cunha, seu "companheiro de lides filológicas desde 
os meus dias de estudante em Madri e Paris, que dava cobertura técnica a essas aventuras matinais". Mas o tempo passou, sua perspectiva também: "Ainda persistia em mim excessiva confiança na estabilidade do saber. Com o passar dos anos minha crença nos saberes compactos, redondos, acabados, foi diminuindo. Passei a supor que todo saber é saber por saber. Pena que não possa me desculpar perante meu fraterno diretor". ${ }^{15}$

Ao falar de sua ascendência intelectual, menciona escritores que se situam no patamar mais alto da literatura brasileira, como Manuel Bandeira e Jorge de Lima, bem como da crítica, dentre eles Augusto Meyer e Alceu Amoroso Lima, seu "descobridor". E, claro, Afrânio Coutinho, que o antecedeu na Universidade Federal do Rio de Janeiro, o mestre que lhe abriu muitas portas. Gratidão, eis outro traço forte de Portella.

Afrânio Coutinho é um caso especial. Portella deve-lhe o convite para escrever algumas de suas melhores páginas. Como as de sua participação na Introdução Geral ao volume Vinicius de Moraes. Poesia completa e prosa, publicado em 1987 pela Editora Nova Aguilar do Rio de Janeiro, organizada por Afrânio com assistência do poeta. $\mathrm{O}$ ensaio crítico de Portella sobre a localização da obra e percurso de Vinicius é modelar, porque profundamente esclarecedor e sensível tanto na perspectiva da história literária como no plano da estilística. ${ }^{16}$

No texto de apresentação da obra de Vinicius, Do verso solitário ao canto coletivo, Portella propõe "uma leitura não-modernista" do poeta, prosador e músico. Mostrando o quanto o poeta "se fez em esforçado relacionamento crítico com os valores do modernismo", observa como era ele refratário ao acervo temático dos homens de 22. Pois sua linhagem vinha do grupo Festa, com Augusto Frederico Schmidt, grande e esquecido poeta, e outros, como Octávio de Faria. Portella define Vinicius como um escritor-ponte entre o modernismo e a "aquela geração nostálgica, que em 1945 empreenderia uma longa viagem de volta" (p.15). Traz ele essa "contradição genética”, escreve o crítico, que o faz o "último grande literato da poesia brasileira e o primeiro grande cantor de uma sociedade de massas" (ibidem):

Como literato é responsável por uma das mais sólidas construções líricas da nossa poesia, embora possamos incriminá-lo por ter sido a estação central de " 45 ", na medida em que foi o restaurador implacável das formas poemáticas exoneradas pela nova ordem de "22". Como compositor, redimensiona a música popular brasileira, faz-se um dos seus fundadores. Popularizou-se.

Para Portella, Vinicius e João Cabral ${ }^{17}$ são escritores que se desclassificaram. Ou seja, não cabem nas classificações tradicionais, formais. Ambos beberam na tradição clássica e depois se libertaram das "formas imóveis" (p.19). E Vinicius bebeu muito mais...

Só mesmo uma sensibilidade inter e transdisciplinar, como a de Portella, seria capaz de tal visão sintética e definitiva (no sentido de definir) do grande poeta, escritor e músico Vinicius. 


\section{Portella: a "baixa modernidade"}

“O intelectual autocentrado, autoritário e autista já não sensibiliza ninguém. Porque deixou de ser a consciência da sociedade, ou porque a sociedade deixou de ter consciência, ou ainda porque a consciência deixou escorrer pelo ralo da história o que fora um dia a sua verdade. Os pedaços, o quase e o que se esquiva para além do quase passaram a ser metáforas vivas de nossa sociedade.”

(Eduardo Portella, Descontrução dos gêneros literários, 2001. $)^{18}$

Vista sua biografia em perspectiva, Portella talvez possa ser definido como um combativo intelectual heterodoxo em tempo integral, contra o saber bem comportado, ainda quando esse desponta sob o rótulo de "moderno". Não quer isso significar que Eduardo Portella não tenha sido propriamente moderno em algum momento de seu percurso, ou quando menos atento e sensível ao modernismo; talvez sim, porém desconfiado dos sucessivos modismos nesses tristes trópicos, que desaguaram no que atualmente se denomina pós-modernidade. ${ }^{19}$ Não por acaso prefere ele, com rigor, definir o último período de nossa História Cultural como "baixa modernidade". Ciente das ambiguidades de nossa condição histórico-cultural, prefere interpretá-la com ligeiro sorriso, falsamente tímido.

Ao comentar um livro de Florestan Fernandes, Tensões na educação, na Revista Tempo Brasileiro em dezembro de 1995, colocou em questão a nossa "modernidade". Ou seja, nossa histórica e grave inatualidade, por conta das "questões pendentes, esse contencioso persistente, no âmbito global ou no facilitário da modernidade". E, como examinaremos mais adiante, sentenciou: "No início do III milênio, ainda nos encontramos às voltas com o legado moderno, sem saber ao certo o que ele possa ter de lição e de mal-entendido". ${ }^{20}$

\section{Poliedro}

Ainda que em termos ensaísticos, como abarcar os diferentes níveis de realidade em que esse escritor, crítico e professor transitou, sempre de cara limpa, ao longo desses 80 anos? E os temas e problemas que enfrentou, assim como as disciplinas do conhecimento com as quais lida e opera, tudo isso provocando o turbilhão criativo que o alimenta e aos seus interlocutores. Observado em perspectiva no mapa político-cultural brasileiro, qual o significado da bem cuidada formação, e da aparente e eventual picardia desse arguto leitor de Montaigne e Voltaire?

Difícil achar uma imagem física para representá-lo. Em 1983, Manuel Antônio de Castro já detectara seu "pensamento prismático". ${ }^{21}$ Penso porém que um poliedro de vidro talvez seja um símile possível, a figura geométrica adequada que nos ajuda a debuxar o perfil do Eduardo ensaísta e crítico da cultura, multiplicado no Eduardo crítico literário e, além de professor aplicado, também 
político cultural, homem de ação, meio filósofo e meio historiador, humanista, enfim. Um poliedro iluminado, brilhante e rodante, através do qual refratam e brilham luzes de diversas cores, em diferentes ângulos, com velocidades e distâncias ora milimétricas ora cósmicas, misturadas.

Um homem de sua época? Ocorre que o clichê é pobre para defini-lo, até porque se trata de personagem que transita por muitas épocas, desses que viajam nos tempos histórico-culturais sem utilização, ou precário conhecimento, de relógio, radar, bússola, internet ou GPS. Mas que possui antenas permanentemente ligadas que captam sons, gestos, sensibilidades, valores, vivências e produções de nosso tempo, como também de outras épocas, na busca infatigável e revelação, por meio de calibrada hermenêutica, da riqueza e complexidade das formas de pensamento ancestrais que nos alcançam nos dias que correm. Com os instrumentos da filologia, da filosofia, da literatura e da historiografia tornou-se um mestre no estudo das formas de pensamento e das mentalidades. Formas de pensamento não apenas escritas, mas desenhadas, professadas, filmadas ou cantadas.

Para ele não há "busca do tempo perdido", nem agonia com um suposto "fim da História", ou desencantamento com o presente. Até porque o "objeto" de suas inquietudes são culturas, civilizações e, mais frequentemente, escritores. ${ }^{22}$ Arqueólogo de camadas mentais insuspeitadas que compõem a vida presente, Portella lê nos textos e signações de antanho a nossa desencontrada contemporaneidade, mas para ele não irrevogavelmente perdida, dado que alimenta a ideia de que o tempo é "matéria da qual somos feitos" (Jorge Luís Borges). E se dedica como poucos em decifrar o tempo, as temporalidades e durações em todas as possíveis dimensões e variações.

Continua.

Notas

l O atentado foi estimulado por um artigo-denúncia de Gustavo Corção no Diário de Notícias sobre as atividades "subversivas" do Colégio. Passado um período de recesso, Eduardo Portella reafirmaria em editorial: "Não temos compromissos senão com a causa do homem e o empenho de construção nacional" (Editorial da Revista Tempo Brasileiro, n.7). Franco Portella foi preso duas vezes: uma de madrugada, em casa, e outra no escritório, detido e encapuzado, por "possíveis atos subversivos", logo desmoralizados (era o Comando de Caça aos Comunistas, o CCC).

2 Ver, por exemplo, seu artigo "Modernidade no vermelho" em I. Sachs; J. Wilheim; P. S. Pinheiro (Org.) Brasil: um século de transformações. São Paulo: Companhia das Letras, 2001. Uma biografia do ensaísta e professor encontra-se em C. Sepúlveda, Eduardo Portella. A linguagem solidária. Rio de Janeiro: Topbooks, 2003, obra em que sinaliza o percurso intelectual, bem como sua ação institucional, política e também editorial como diretor da Revista Tempo Brasileiro, doravante citada como Rev.TB. Sobre a revista, ver o artigo de Portella "O argumento Tempo Brasileiro", na revista Estudos Avançados, v.24, n.69, dirigida por Alfredo Bosi, USP, 2010. 
3 É ainda em Camus que colhe inspiração para sua posição de espírito na atualidade: "O homem revoltado deve saber medir a sua revolta". Ver o breve ensaio de sua autoria "É preciso imaginar Albert Camus feliz", na Revista Brasileira, v.65, Academia Brasileira de Letras, out.-dez. 2010, Ano XVII.

4 Segundo a crítica Maria Esther Vazquez, em Babelia, suplemento cultural do El País, Madri, 8.12.2007, p.10. Borges "resignou-se em carregar sua imagem pública, talvez por cansaço". Quanto a Naipaul, desconte-se seu mau humor costumeiro.

5 Ibidem.

6 No Simpósio “Censura: Histórico, Situação e Solução", realizado na capital federal no período de 16 de maio a 30 de agosto de 1979, coordenado pelo bravo deputado Israel Dias-Novaes, um liberal autêntico e histórico, tendo como relatores os deputados Albérico Cordeiro e Cristina Tavares.

7 Neste ensaio, apresentamos apenas alguns aspectos de sua personalidade e de sua vasta obra. Um perfil de Eduardo Portella, que abrange sua trajetória desde o início, em várias frentes de atuação, foi elaborado por Carlos Sepúlveda em Eduardo Portella. A linguagem solidária (op. cit., 2003). Em anexo, inclui um depoimento de Clarice Lispector. Ainda em 2003, a Academia Brasileira de Letras publicou volume Homenagem a Portella, com apresentação de Alberto da Costa e Silva (Rio de Janeiro: Academia Brasileira de Letras, 2003), contendo textos analíticos e apreciações sobre sua obra e atuação, entre os quais os de Eduardo Coutinho, Candido Mendes, Ivan Junqueira, Nélida Piñon, Almir Madeira e Carlos Heitor Cony; mais diretamente sobre o perfil filosófico de Portella, os textos de Tarcísio Padilha e Sérgio Paulo Rouanet, além de um perfil biobibliográfico (e cronológico) elaborado por Domício Proença Filho. Em resposta, o professor e crítico fez um balanço de suas posições de então. Ainda para sua biografia, ver também o breve estudo introdutório de Claudius Waddington ao livro México: Guerra e Paz (Rio de Janeiro: Tempo Brasileiro, 2001), obra com ensaios sobre Octávio Paz, Juan Rulfo e Carlos Fuentes. Os 30 primeiros anos de sua vida intelectual foram analisados em Eduardo Portella: ação e argumentação (Rio de Janeiro: Edições Antares, 1985, organização de Márcio Tavares D’Amaral), reunindo vários escritores e críticos de diferentes quadrantes, entre os quais Rafael Gutierrez Girardot, Tristão de Athayde, Gilberto Freyre, Juan Rulfo, Afrânio Coutinho, Josué Montello, Eduardo Prado Coelho, Félix de Athayde, Muniz Sodré e Vamireh Chacon (que escreveu sobre a formação intelectual do grupo-geração de Portella, "uma aberta proposta geracional”). Ao completar 40 anos, a revista que dirige publicou um número comemorativo substancioso.

8 Cf. Carlos Sepúlveda, Eduardo Portella. A linguagem solidária (op. cit., 2003, p.43).

9 O livro de José Honório saiu também em inglês em edição da University of California Press, em 1965. Houve edições mais atualizadas, abrangendo o período de 1961 a 1980, tratando das independências das ex-colonias e as novas relações com o Brasil. Sobre o historiador, consulte-se a excelente análise biobibliográfica de autoria de Francisco Iglésias, "José Honório Rodrigues e a Historiografia Brasileira", na revista Estudos Históricos, Rio de Janeiro, 1988/1, p.55-77.

10 O regime salazarista proibiu a circulação das obras de vários autores (“defesos”), entre eles Charles R. Boxer, José Honório Rodrigues, Florestan Fernandes, Caio Prado Júnior e o próprio Portella. Muitos intelectuais, como Vitorino Magalhães Godinho e Joel Serrão, perderam suas cátedras na universidade. Outros foram presos durante anos e até décadas, ou exilados. 
11 Cf. Eduardo Portella. ação e argumentação, op. cit., 1985 p.160, no artigo "O novo acadêmico Eduardo Portella”. O crítico e professor assumira em 1981 a Cadeira n.27 da Academia Brasileira de Letras, que tem por patrono Maciel Monteiro e, fundador, Joaquim Nabuco.

12 Para uma melhor percepção da vida cultural e mental da Espanha de então, e das primeiras décadas do século XX, vale a leitura Meu último suspiro, a autobiografia de Luís Buñuel, do grupo-geração de Garcia Lorca.

13 A temática da educação e do ensino sempre esteve presente em suas cogitações, embates e pesquisas. Ao longo do percurso, produziu textos e intervenções fundamentais, como "A curva sinuosa da Educação" (Rev.TB, Rio de Janeiro, n.151, out.-dez. 2002). Defensor da Pedagogia da Qualidade, deu conferências, lecionou e escreveu obras como Retrato falado da educação brasileira (1980), Educação brasileira: opção social (1980), Universidade, agente de qualidade (1980), Participação e espírito público (1981). Ao tomar posse na Academia Brasileira de Educação, fez discurso sobre Anísio Teixeira, um de seus inspiradores, publicado com o título "Educação e Estado" (1980). Mais recente, a conferência na Academia Brasileira de Letras, "Educação, insubstituível opção" (publicada na Revista Brasileira, Rio de Janeiro, Fase VIII, abril-maio-junho 2012, ano I, n.71), no "Ciclo Pensar hoje”, sob a coordenação de Marco Lucchesi.

14 No volume em Homenagem a Eduardo Portella. "Universidade das Humanidades", Rio de Janeiro: ABL, 2003, apresentação de Alberto da Costa e Silva, p.7.

15 Ibidem, p.5.

16 Embora o ensaio sobre Vinicius seja deveras brilhante, outros merecem ser mencionados, como o fez Claudio Murilo Leal quando do cinquentenário da publicação de $D i$ mensões $I$, onde ressaltou a capacidade do crítico de mesclar o enfoque científico para análise e interpretação do texto e "os elementos intrínsecos do poema, ou da prosa ficcional, com a valoração dos elementos formais, hoje ditos significantes, isto é, os estratos fônicos, rítmicos, a imagética, as metáforas, o vocabulário, em outras palavras, tudo que conformasse o estilo de um autor". Ou seja, do modo que de fato Portella escreveu, diz Murilo Leal, "com extrema acuidade e perspicácia nos ensaios sobre Cassiano Ricardo, João Cabral de Melo Neto, ou José Paulo Moreira da Fonseca, ou sobre Guimarães Rosa, Cyro dos Anjos e Antônio Callado”. Com esse tipo de crítica, disse-o com graça, "o flanêur literário saía de moda". Cf. Homenagem a Eduardo Portella no Cinquentenário da Publicação de Dimensões I (Rio de Janeiro: PEN Clube do Brasil, em convênio com a Academia Brasileira de Filologia, 2008, p.11.

17 "Nem modernista, nem modernoso. Simplesmente moderno. [...] O seu preciso divisor de águas colocou na outra margem os contramodernos, os neoconservadores, os pós-modernos e os baixo-modernos", escreveu Portella em breve texto de despedida, quando do falecimento de João Cabral (Rev.TB, n.139, p.236, out.-dez. 1999). Definição que também serviria para ele próprio...

18 Rev.TB, fase VII, abril-junho 2011, Ano XVII, n.67. Separata, ABL, p.16-17.

19 Na revista que dirige, publicou na década de 1990 volume polêmico sob o título "Avatares da Modernidade" (Rev.TB, Rio de Janeiro, n.118-119, 1994), dedicado à temática da Modernidade e da Pós-Modernidade, com artigos de Marc Jimenez, sobre a Sindrome Pós-moderna, de Sérgio Paulo Rouanet, sobre Voltaire e a Modernidade, de Jean-Philippe Catonné, sobre Foucault e a Modernidade, entre outros. A questão 
da Modernidade reponta em vários números da revista, por vezes focalizando problemas da História da Cultura (com artigos de Michel Maffesoli, Claudius Waddington etc.), ou obras literárias, como é o caso do estudo de Lucia Helena, "Modernidade e contramodernidade em Guimarães Rosa" (Rev.TB, Rio de Janeiro, n.150, jul.-set. 2002). Ou, ainda, voltando-se para o campo filosófico, como no denso estudo de Barbara Freitag sobre "Habermas: do intelectual ao cidadão do mundo" (Rev.TB, Rio de Janeiro, n.138, jul.-set. 1999) e, no mesmo número, o próprio Portella pontua o assunto em "A querela de Modernos e Pós-modernos".

20 O comentário de Portella ao livro de Florestan Fernandes, Tensões na Educação (Salvador: Editora SarahLetras, 1995), foi publicado na Folha de S.Paulo e na revista Tempo Brasileiro (Rio de Janeiro, n.122/123, p.167-71, jul.-dez. 1995), em um conjunto de três resenhas "As diferenças da Identidade. A propósito do caso brasileiro". Em nota, o autor informa que "o artigo foi escrito por solicitação da Folha de S.Paulo, e entregue antes da prematura morte do saudoso mestre brasileiro".

21 Manuel Antônio de Castro, “O pensamento prismático de Eduardo Portella” (in Eduardo Portella. Ação e Argumentação. 30 anos de vida intelectual. Márcio Tavares d'Amaral (Org.) Rio de Janeiro: Edições Antares, 1985). A publicação comemorava então os 30 anos da edição em 1983 em Madri de seu ensaio Aspectos de la poesia brasileña contemporánea. Não é descabida essa maneira de abordar um personagem, pois Raymundo Faoro utilizara-se das imagens da pirâmide e do trapézio para analisar a concepção social de Machado de Assis. E Francisco Alambert também utilizou-se da geometria ao interpretar Sérgio Milliet como "intelectual oblíquo"... Recordando que intelectuais "quadrados" são muitos e os "chatos" não são poucos, como observara Faoro em 1986. Questão de Geometria Analítica.

22 Portella não se furta ao comentário a filmes como O selvagem da ópera, de Rubem Fonseca, inspirado na vida de Carlos Gomes. Cf. "O civilizado contador de histórias" (Rev.TB, Rio de Janeiro, v.118-19, jul.-dez. 1994).

RESUMO - Estudo do perfil biobiliográfico do crítico, professor e ensaísta Eduardo Portella, um dos principais intelectuais do Brasil contemporâneo. $\mathrm{O}$ artigo detém-se na análise de sua formação, acompanhando a trajetória do intelectual público (escritor, publicista, administrador cultural) desde os tempos de estudante na Faculdade de Direito em Recife, depois em sua estada na Europa (na Espanha, mais demoradamente, quando estudou com os mestres da Escola de Madri Bousõno, Zubiri, Marías) e, finalmente, no Rio de Janeiro, onde reside e desenvolve as atividades de escritor e homem de cultura. Tendo exercido as funções de professor de Teoria Literária na Universidade Federal do Rio de Janeiro (na qual é Professor Emérito); ocupou também altos postos em instituições e atividades culturais no Brasil e no exterior, como o Ministério de Educação e Cultura, em Brasília, a presidência da Fundação Biblioteca Nacional, no Rio de Janeiro, e a direção da Unesco, em Paris. Fundou no Rio de Janeiro o Colégio do Brasil e criou, há 50 anos, a Revista Tempo Brasileiro, uma das mais prestigiosas do país. É autor de várias obras, entre elas a série Dimensões (em quatro volumes); O intelectual e o poder; Vanguarda e cultura de massa; Literatura e realidade nacional; Teoria da comunicação literária; Teoria Literária, fundamento da investigação literária e Homem, cidade, na- 
tureza, além de importantes ensaios. Pertence a diversas instituições culturais e, desde 1981, é membro da Academia Brasileira de Letras.

PALAVRAS-CHAVE: Teoria literária, Ensaio, História da cultura, Cultura brasileira, Educação, Escola de Madri, Academia Brasileira de Letras, Literatura, Modernidade, Cultura de massa, Vinicius de Morais, Sérgio Milliet.

ABSTRACT - This essay is a study of the biobibliographic profile of the critic, professor and essayist Eduardo Portella, a leading intellectual of contemporary Brazil. It analyzes his early development and follows his path as a public intellectual (writer, publicist, cultural manager) from his years as a Law School student in Recife to his sojourn in Europe (particularly in Spain, where studied with Bousõno, Zubiri, and Marías, masters of the School of Madrid) and, finally, to Rio de Janeiro, where he now lives and works as a writer and man of culture. Portella was professor of Literary Theory at the Federal University of Rio de Janeiro (where he is Professor Emeritus), and also held senior positions in cultural activities and institutions in Brazil and abroad, including the Ministry of Education and Culture, in Brasilia, the presidency of the National Library Foundation, in Rio de Janeiro, and the direction of Unesco, in Paris. Portella founded the Colégio do Brasil in Rio de Janeiro, and, 50 years ago, launched Tempo Brasileiro, one of the country's most prestigious journals. Portella is the author of several works, including the 4-volume series Dimensões; O intelectual e o poder; Vanguarda e cultura de massa; Literatura e realidade nacional; Teoria da comunicação literária; Teoria literária, Fundamento da investigação literária and Homem, cidade, natureza, in addition to many significant essays. He is a member of various cultural institutions and, since 1981, of the Brazilian Academy of Letters.

KEYWORDS: Literary theory, Essay, History of culture, Brazilian culture, Education; School of Madrid, Brazilian Academy of Arts, Literature, Modernity, Mass culture, Vinicius de Morais, Sérgio Milliet.

Carlos Guilherme Mota, historiador, é Professor Emérito da Faculdade de Filosofia, Letras e Ciências Humanas. Ex-diretor e Professor Honorário do Instituto de Estudos Avançados da USP, é professor titular de História da Cultura na Universidade Presbiteriana Mackenzie. @-cgsmota@terra.com.br

Recebido em 11.9.2012 e aceito em 21.9.2012. 